\title{
Power Quality Measurements and Operating Characteristics of Electric Arc Furnaces.
}

\author{
Pedro E. Issouribehere (*),Fernando Issouribehere $(*)$ IEEE Student Member, and Gustavo A. Barbera $\left(^{*}\right)$
}

\begin{abstract}
Power quality is of increasing concern to utilities and their customer alike. Many loads connected to electric power systems can cause power quality problems at all voltage levels and for very different power ratings due to their unbalanced and non-linear behaviour characteristics.

This paper describes the aspects of power quality at the point of common coupling (PCC) where an arc furnace for steel melting with alternating current is connected. By measurements of flicker, harmonics content in voltage and current, active and reactive power and power factor, the preservation of the reference levels for the supply voltage and emission limits for the furnace as a customer are evaluated.

The evaluation of the power quality of contemporary International and Argentinian standards is given.

The different phases in the operation of the arc furnace are described in detail and illustrated with measurements, and a complete single phase equivalent circuit for the arc furnace is obtained from field tests.
\end{abstract}

Index Terms - Arc Furnaces. Power Quality. Flicker. Harmonics.

\section{INTRODUCTION}

$\mathrm{I}$ $\mathrm{n}$ order to ensure the electromagnetic compatibility in distribution networks, the perturbation levels in different points of them must be confined to certain limits [5] and [6], process that involves a permanent control of emissions due to every disturbing load connected to the network.

Electric arc furnaces loads can result in serious electrical disturbances on a power system. Low level frequency modulation of the supply voltage of less than $0.5 \%$ can cause annoying flicker in lamps and invoke public complaints when the frequencies lies in the range of $3-10 \mathrm{~Hz}$.

An 8-tons electric arc furnace of 2.5 MW for steel melting is connected in the $13.2 \mathrm{kV}$ voltage level in the Distribution System of Buenos Aires (Argentina). The IITREE has made measurements of some power quality quantities to check the reference levels at the PCC and the emission limits of the arc furnace as a consumer. The quantities measured are voltage and current harmonics, flicker, power factor and active and reactive power.

Field tests were done to obtain the complete set of parameters for the determination of a single phase equivalent electric circuit of the arc furnace. The measurements made during the several phases in the operation of the arc furnaces

(*) Pedro E. Issouribehere, Fernando Issouribehere, and Gustavo A. Barbera are with IITREE-LAT. Facultad de Ingeniería Universidad Nacional de La Plata. (1900) 48 y 116. La Plata. Argentina (e-mail: iitree@iitree-unlp.org.ar). support the validity of the single-phase model.

Technical solutions for flicker emission problem are presented.

\section{DESCRIPTION OF THE POWER SYSTEM AND PCC}

The configuration of the power system is shown in Fig. 1.

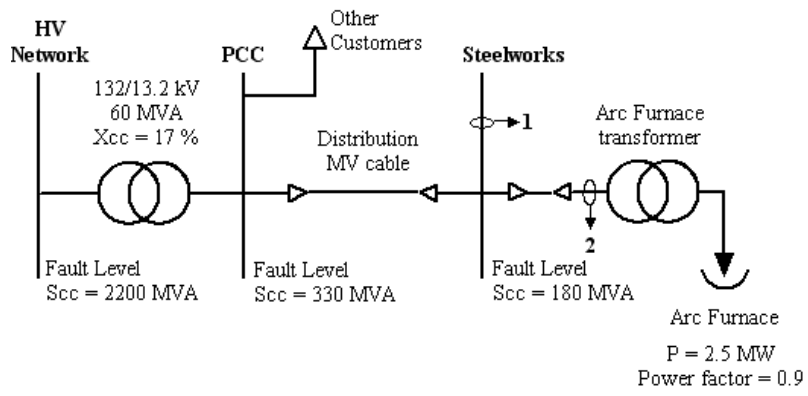

Fig. 1: Electrical system configuration.

As is shown in Fig. 1, the steelworks it is supplied directly from public distribution network at $13.2 \mathrm{kV}$. As will be demonstrated in this paper, the short circuit power at the steelworks substation is not optimal from the point of view of power quality.

As is seen from Fig. 1, the two points where the measurements were made are: point 1 in the steelworks supplying point, and point 2 in the measuring transformers on the primary side of the arc furnace transformer.

\section{Characteristics OF ElECTRIC ARC FURNACES}

An electric arc furnace consists of a refractory lined shell which holds the charge, usually scrap metal. Three large electrodes, usually of graphite, are held in special clamps on a swing support structure which can be swung aside for charging, and which allows each electrode to be raised or lowered according to the output of the control system.

After the furnace is charged with scrap, operation begins by lowering the electrodes to strike electric arcs between the electrodes and the scrap. The heat generated by the three electric arcs provides the heat for melting and refining the scrap.

Steel making from electric arc furnaces is a batch type operation .

There are several phases in the operation of the arc furnace with each presenting a different impact on the power system in terms of flicker, namely the:

- $\quad$ Boring period.

- Melting period.

- $\quad$ Refining period. 
Fig. 2 shows the theoretical variation in the power level of the furnace during a typical furnace heat [3]. As indicated, after the initial boredown and meltdown period, the furnace is recharged one or more times during the heat to avoid unreasonably large furnace volumes.

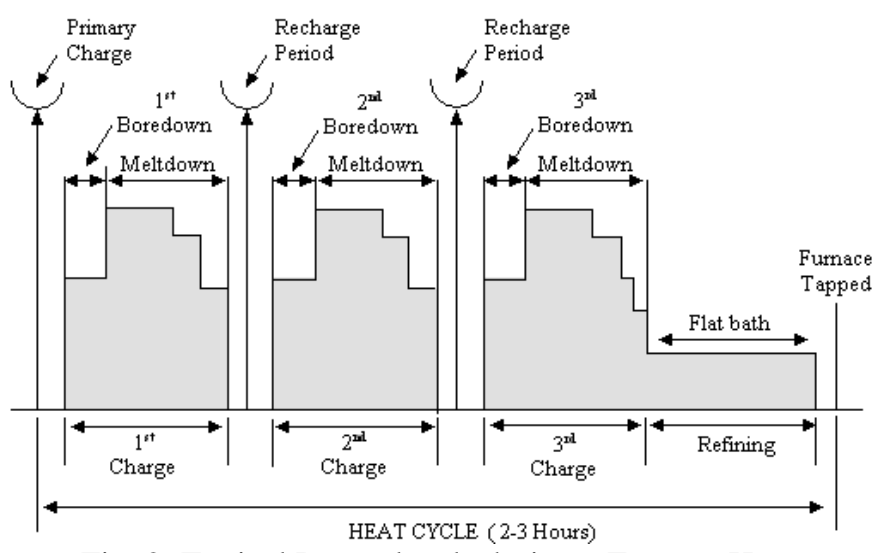

Fig. 2: Typical Power levels during a Furnace Heat.

Fig. 3 shows the Active Power measured in the arc furnace. It is possible to distinguish from this figure the three phases previously mentioned in the operation of the arc furnace.

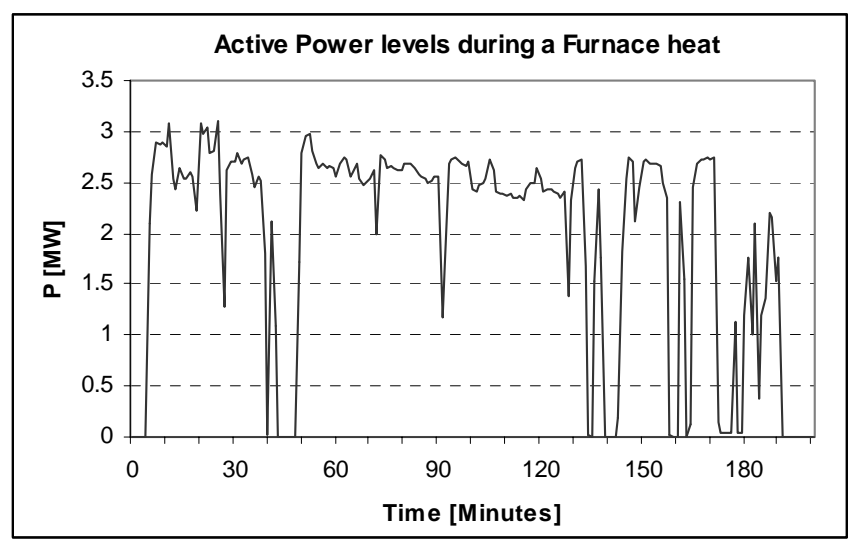

Fig. 3: Power levels measured during a Furnace Heat.

Due to the random motion of the electric arc, and resulting changes in the arc length, there are random fluctuations in current which in turn cause voltage fluctuations up-stream of the furnace in proportion to the system impedance.

Depending on the operating states, the furnace load may change from a complete open circuit to a 3-phase short circuit. During normal operation irregular voltage fluctuations will occur as a consequence of arc movement.

Repetitive voltage fluctuations in power systems need to be controlled within reasonable low levels to reduce their impact on domestic and commercial customers to an acceptable level. The main reason for such control actions is the effect of arc furnace operation on the light output of incandescent electric lighting i.e., flicker, that can cause irritation for the eye and therefore to the human beings.

In terms of flicker impact on the power system the most critical stages are the boring and melting periods, which occur every time a new basket with scrap metal is added.
These periods are characterized by strong stochastic variations in the reactive power absorbed by the arc furnace from the power system. Refining period is less critical in this respect. This behaviour of the electric arc furnace should be seen in the measurements made.

The power input of the furnace is very sensitive to voltage variations. Thus efficient operation of an electric arc furnace requires a constant and stable voltage supply.

In practice to achieve a stable furnace operation, the power factor for the furnace needs to be maintained between 0.7 and 0.8 i.e., the reactive power drawn by the furnace needs to be in the same range as the active power. The reactive power drawn by the furnace will have a major impact on the feeding voltage and during operation will create a voltage drop on the primary side of the furnace transformer.

The voltage drop on the primary side of the furnace transformer will consequently give lower available melting power. Given the continuously changing nature of the arc, dynamically responsive reactive compensation such as SVC or STATCOM able to stabilize the voltage of the feeding network during the whole scrap charge is essential.

With the stabilized voltage created by the reactive compensation i.e., SVC or STATCOM , the power-on-time of the furnace will be reduced. As a consequence, energy saving will be achieved.

In order to appreciate the benefits of voltage stabilization to the furnace, it is necessary to look at the furnace operating characteristics. These can be derived as follows.

The arc can be represented as a variable resistance in a simple single phase equivalent of the furnace and its supply system, as it is shown in Fig. 4.

Although this model is a simplification of the real furnace and implies balanced arc furnace operation, it gives accurate account of furnace operation in terms of averaged quantities, as will be demonstrated by measurements.

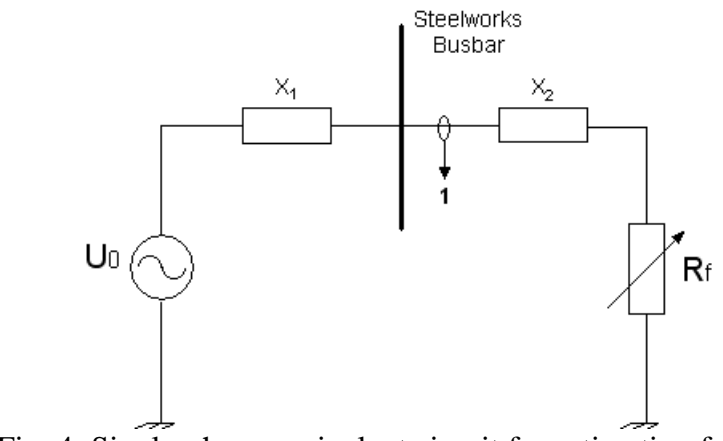

Fig. 4: Single-phase equivalent circuit for estimating furnace characteristics.

The point numbered 1 in Fig. 4 is the one where measurements were made. The reactance $X=X_{1}+X_{2}$ includes the reactances of the flexible leads, the electrodes, the furnace transformer, and the short circuit reactance of the supply network.

Control of the circuit of Fig. 4 is by vertical movement of the graphite electrodes, which controls the arc length and therefore its voltage, and by varying the transformer's taps, which varies $\mathrm{U}_{0}$. 
The power which can be delivered to the load (i.e., the arc) as $\mathrm{R}_{\mathrm{f}}$ varies is limited to the maximum one phase value:

$$
P \max =\frac{E^{2}}{2 X}
$$

The value of $\mathrm{Rf}$ at the maximum power condition is:

$$
R P \max =X
$$

And the current corresponding to the maximum power is:

$$
I P \max =\frac{E}{\sqrt{2} X}
$$

The voltage across the arc is then equal to the voltage drop across $X$, both equal to $E / \sqrt{2}$.

It is possible from field test to estimate the reactances $\mathrm{X} 1$ and $\mathrm{X} 2$ and the short circuit voltage depression ratio.

If the electrodes are immersed in the liquid scrap, the load will be a 3-phase short circuit, which is equivalent to make $\mathrm{Rf}=0$ in Fig. 4.

In this operating conditions, the IITREE measured 3-phase voltages and currents in point 1 . Fig. 5 shows voltage and current waveforms for one phase, and Fig. 6 shows the 3phase power factor and active and reactive power variations during the test.

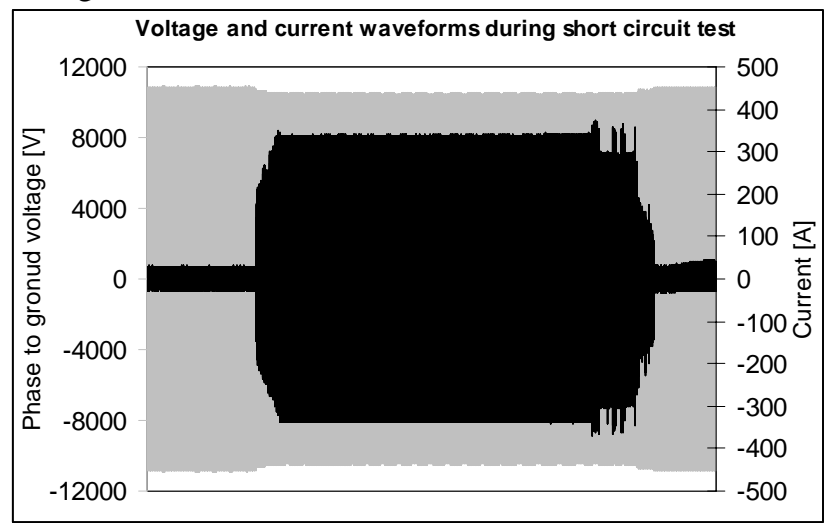

Fig. 5: Voltage and current waveforms measured during the short circuit test.
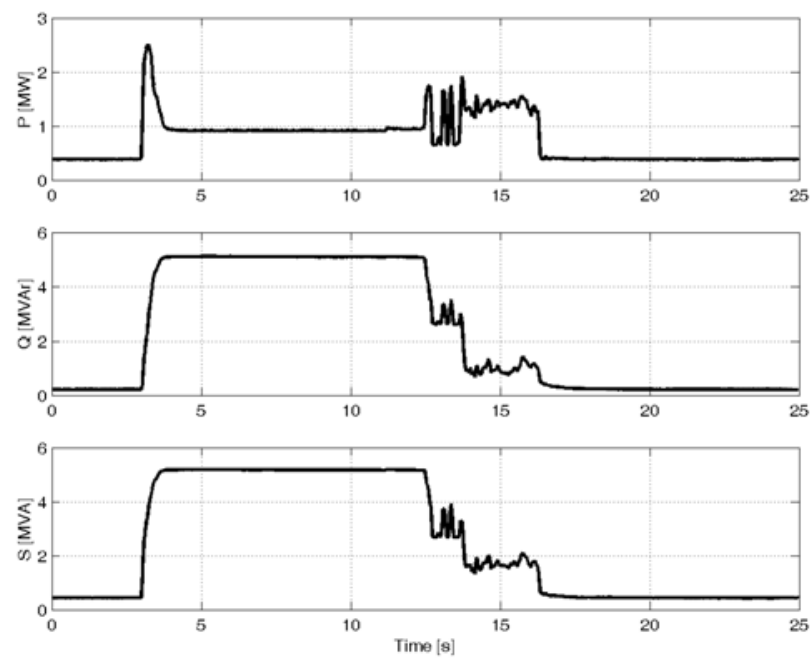

Fig. 6: Power factor and Active and Reactive power variations during the short circuit test.
The short circuit test is of fundamental importance to estimate the operating characteristics of the electrical arc furnace. The parameters obtained from this test are:

- The short circuit reactance of the supply network:

$$
X_{1}=\frac{\left|U_{0}-U_{c c}\right|}{I_{c c}}=\frac{\left|10.853 \times 10^{3}-10.523 \times 10^{3}\right|}{345.3}=0.95 \Omega
$$

- The reactance of the flexible leads, the electrodes and the furnace transformer:

$$
X_{2}=\frac{U_{c c}}{I c c}=\frac{10.523 \times 10^{3}}{345.3}=30.5 \Omega
$$

- The short circuit power at the steelworks substation:

$$
S_{s c}=\frac{U_{L}^{2}}{X 1}=\frac{\left(13.28 \times 10^{3}\right)^{2}}{0.95}=185 \mathrm{MVA}
$$

- The furnace short circuit power:

$$
S_{s c f}=S_{s c} \frac{\left|U_{0}-U_{c c}\right|}{U_{0}}=5.6 \mathrm{MVA}
$$

It is possible now to estimate the general load variations of the electric arc furnace by using the equivalent circuit shown in Fig. 4. The results are shown in Fig. 7.

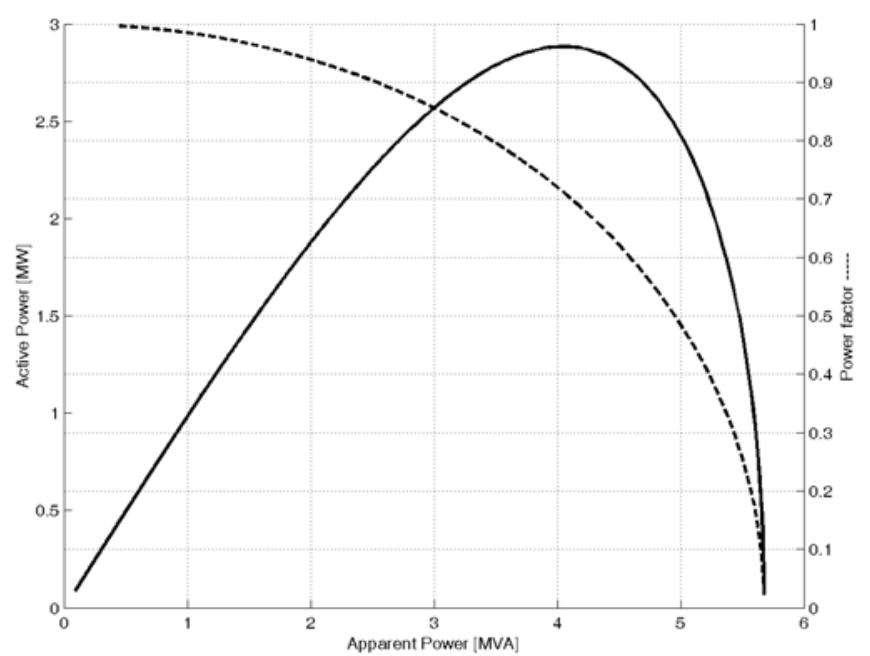

Fig. 7: Furnace operating characteristics.

It is interesting now to analyze the operating characteristics and the harmonics generated during the several phases in the operation of the electric arc furnace. The phases analyzed are Boring and Melting period in the primary charge and Refining.

The measurement of phase voltages and currents were made with a HIOKI 8840 Memory Hicorder, with 8 isolated channels, 12 bits, 200 ksamples/s. The sampling frequency adopted was 2 ksamples/s.

\section{A. Boring period}

This period is characterized by strong variations of active and reactive power caused by stochastic variations in the arc length due to the irregular surface of the scrap metal.

The results obtained from measurements are shown in Fig. 8, 9 and 10. It is very interesting to note from Fig. 8 the similitude between the measured points and the theoretical 
characteristics of the electrical arc furnace obtained from short circuit test.

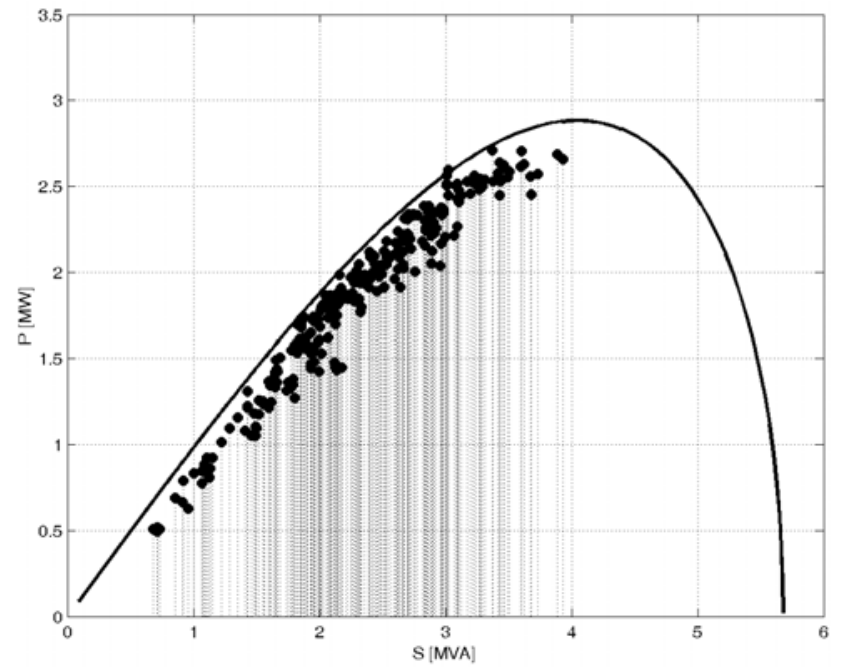

Fig. 8: Theoretical and real P-S characteristics of the electric arc furnace during Boring period.
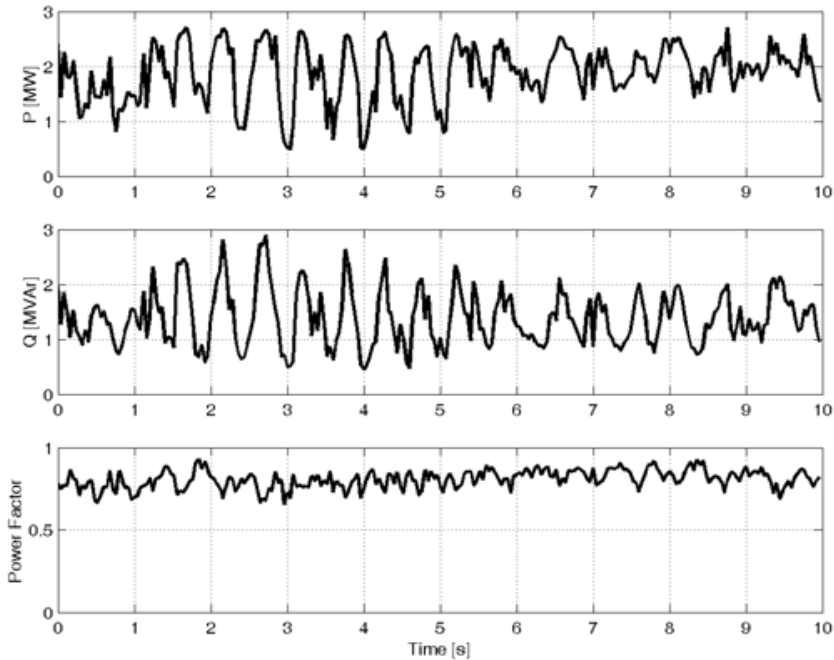

Fig. 9: Power factor and active and reactive power during Boring period.

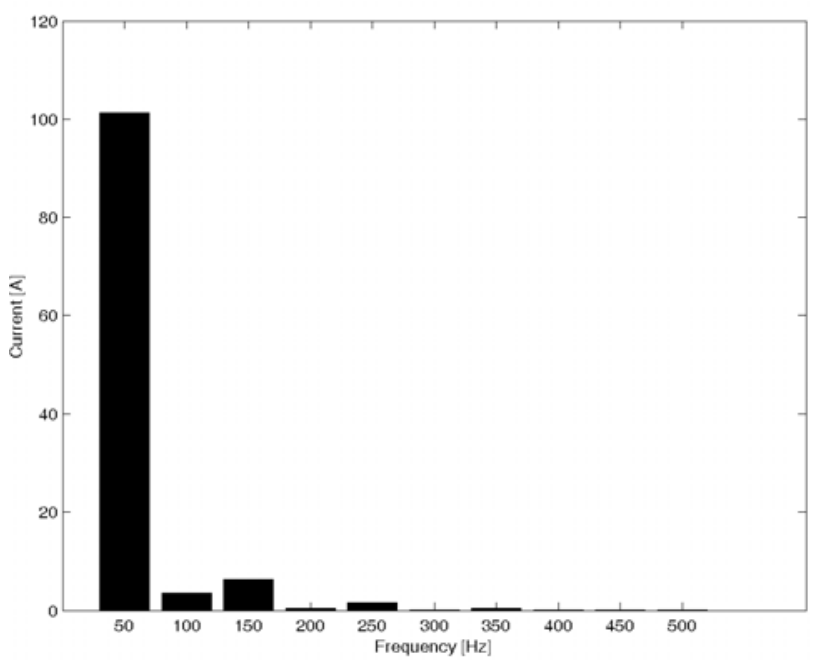

Fig. 10: Harmonic content of arc furnace current.

\section{B. Melting period}

The results obtained from measurements taken in this period are shown in Fig. 11, 12 and 13.

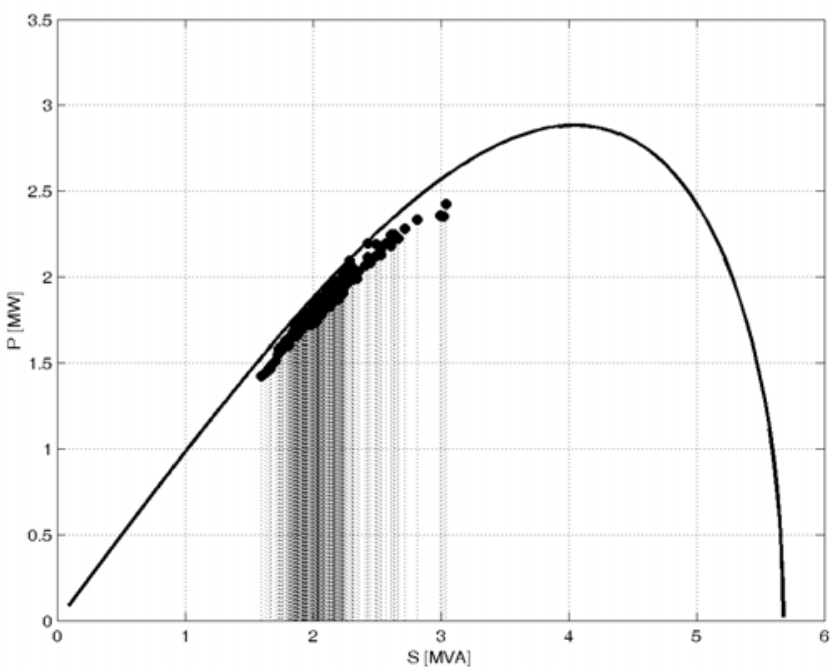

Fig. 11: Theoretical and real P-S characteristics of the electric arc furnace during Melting period.
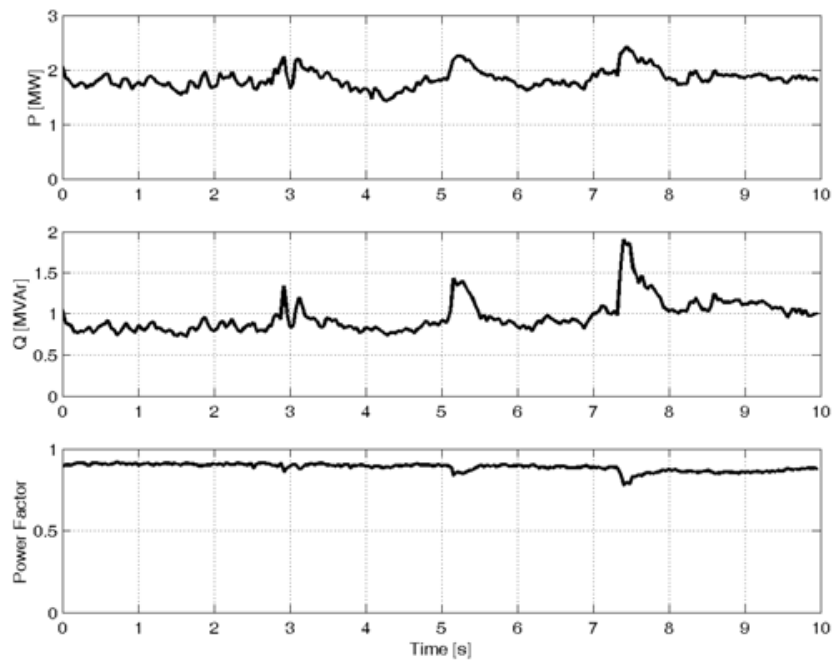

Fig. 12: Power factor and active and reactive power during Melting period.

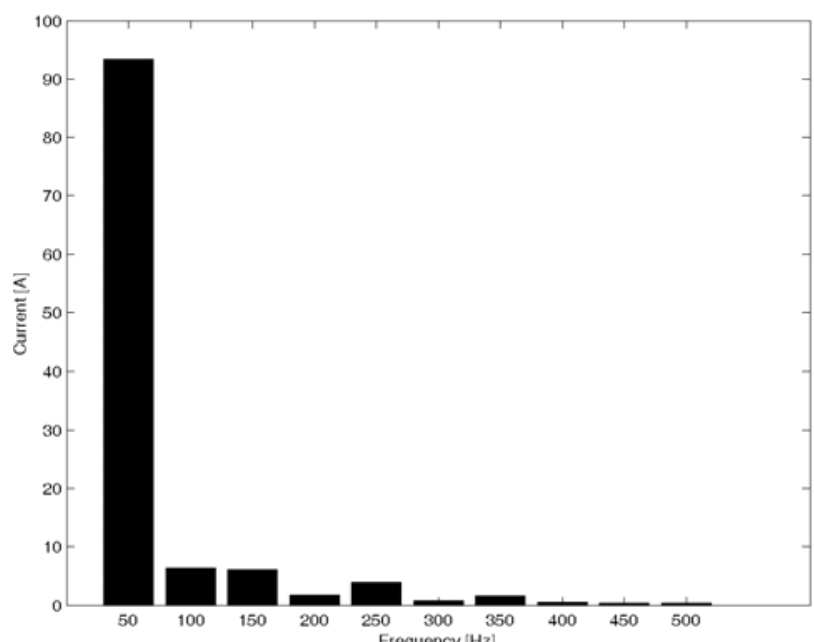

Fig. 13: Harmonic content of arc furnace current. 


\section{Refining period}

The results obtained from measurements taken in this period are shown in Fig. 14, 15 and 16.

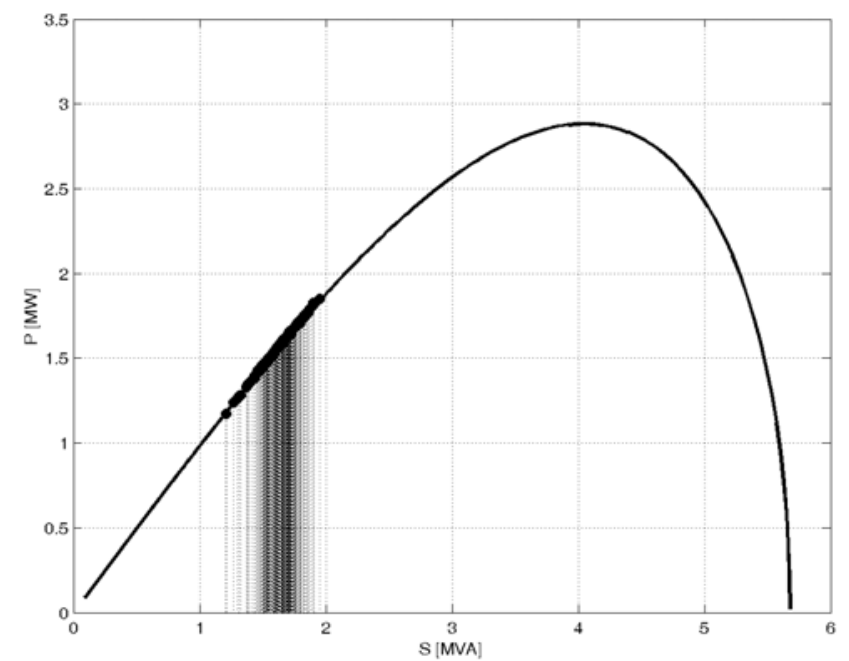

Fig. 14: Theoretical and real P-S characteristics of the electric arc furnace during Refining period.
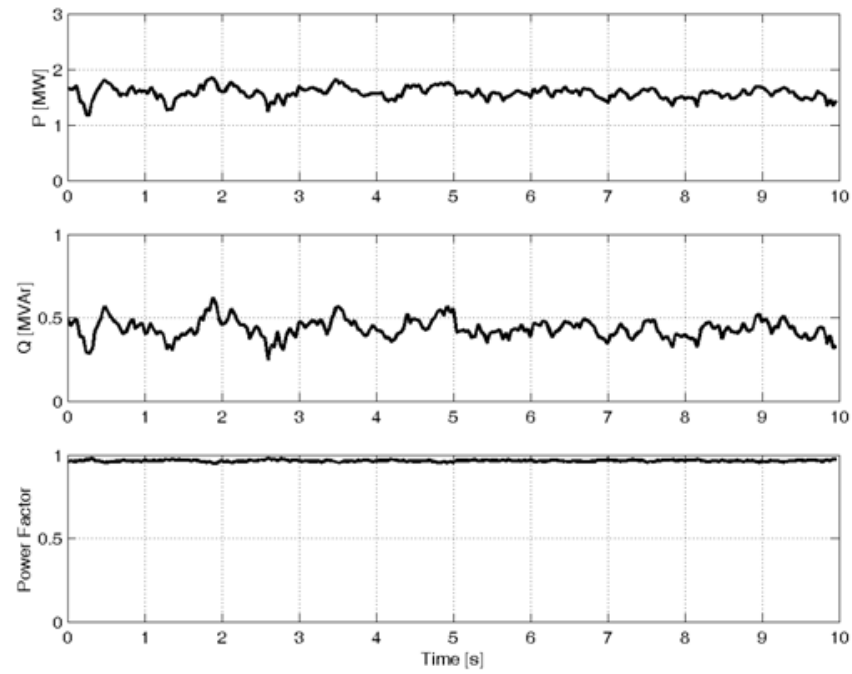

Fig. 15: Power factor and active and reactive power during Refining period.

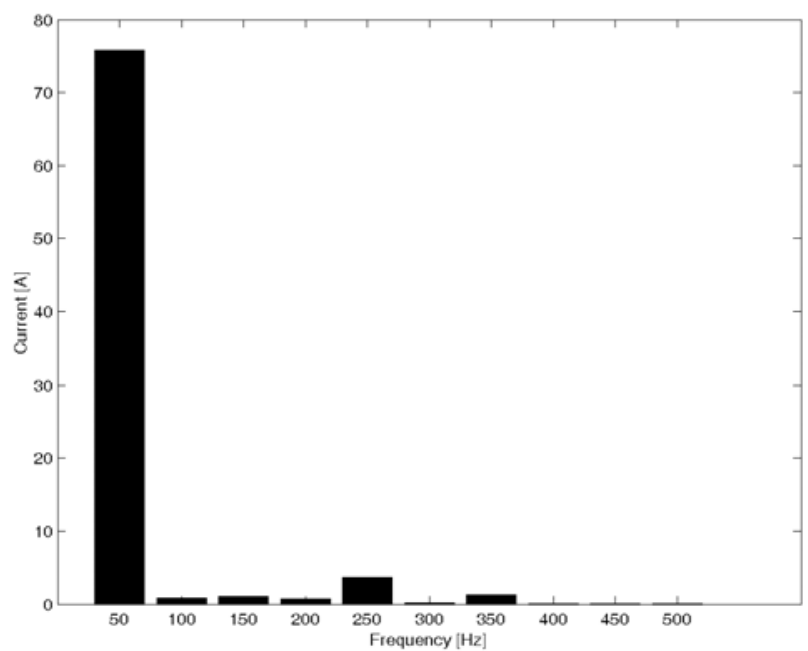

Fig. 16: Harmonic content of arc furnace current.
Table I summarizes the results of harmonic content of arc furnace current described in IEEE 519 Standard [6], and the results obtained from measurements.

Table I: Harmonic content of arc furnace current

\begin{tabular}{|l|l|c|c|c|c|c|}
\hline \multirow{2}{*}{$\begin{array}{l}\text { Furnace } \\
\text { Condition }\end{array}$} & \multicolumn{5}{|c|}{ Harmonic current [\%] of } \\
& & $\mathrm{I}_{2}$ & $\mathrm{I}_{3}$ & $\mathrm{I}_{4}$ & $\mathrm{I}_{5}$ & $\mathrm{I}_{7}$ \\
\hline \multirow{2}{*}{$\begin{array}{l}\text { Initial melting } \\
\text { (active arc) }\end{array}$} & Theoretical & 7.7 & 5.8 & 2.5 & 4.2 & 3.1 \\
\cline { 2 - 8 } & Measured & 6.7 & 6.4 & 1.8 & 4.2 & 1.6 \\
\hline $\begin{array}{l}\text { Refining } \\
\text { (stable arc) }\end{array}$ & Theoretical & - & 2.0 & - & 2.1 & - \\
\cline { 2 - 8 } & Measured & 1 & 1.4 & 0.9 & 4.8 & 1.6 \\
\hline
\end{tabular}

The arc furnace currents are unbalanced, distorted, and fluctuate by large amounts even between consecutive half cycles. As it can be seen in Table I, the distortion tends to be more severe during the first few minutes of the melting cycle. As the pool of molten metal grows, the arc becomes shorter and more stable and the subsequent Refining period is characterized by much steadier currents with relatively little distortion.

The results presented in the first part of this paper tend to analyze the behaviour and the operating characteristics of the electrical arc furnace. In the next section, some power quality quantities will be compared to the reference levels described in Standards and Recommendations. The quantities measured are flicker and harmonics in voltage and current.

\section{STANDARDS AND RECOMMENDATIONS}

It is responsibility of utilities and/or power system operators to ensure the electromagnetic compatibility (EMC) of the whole system and the equipment connected to it. In this respect compatibility levels have to be considered as reference values for the coordination of emission and immunity of equipment connected to the power network. The compatibility levels have to be considered on statistical basis, generally adopting the principle that the levels chosen will not be exceeded in both time and space with a 95\% probability.

\section{IV.1 Flicker}

IEC Standards 61000-2-1 [3] and 61000-2-2 [4] are the general standards which respectively define the different types of disturbances in power systems and the compatibility levels for low voltage (LV) public networks. Flicker compatibility levels for $\mathrm{LV}$ and $\mathrm{MV}$ networks, in terms of $\mathrm{P}_{\mathrm{st}}$ and $\mathrm{P}_{\mathrm{lt}}$ are described in Table II.

Table II: Summary of IEC Flicker compatibility levels.

\begin{tabular}{|c|cc|}
\hline \multicolumn{3}{|c|}{ Compatibility Levels } \\
\hline \multirow{3}{*}{ LV/MV } & $\mathbf{P}_{\text {st }}$ & $\mathbf{P}_{\mathrm{lt}}$ \\
\cline { 2 - 3 } & 1.0 & 0.8 \\
\hline
\end{tabular}

For assessment purposes, the minimum period of observation should be one week, and the $\mathrm{P}_{\mathrm{st} 99 \%}$ and $\mathrm{P}_{1 \mathrm{t} 99 \%}$ values resulting from the measurements should be compared with the allowed relevant 99\% emission limits. Concerning 95\% values instead 
of $99 \%$ it is suggested on the basis of results of several measuring periods, the following relationships:

$$
\begin{aligned}
\mathrm{P}_{\mathrm{st} 99 \%} & =1.25 \mathrm{P}_{\mathrm{st} 95 \%} \\
\mathrm{P}_{\text {lt95\% }} & =0.8 \mathrm{P}_{\mathrm{st} 95 \%}
\end{aligned}
$$

Flicker measurements where made by the IITREE with the IEC 60868 normalized flickermeter Boconsult B9-DSP and with Topas 1000.

Fig 17 shows the results obtained from a $\mathrm{P}_{\mathrm{st}}$ measurements in 1-minute interval during a complete furnace cycle. This non normalized measurement was performed to evaluate flicker severity caused by rapid voltage fluctuations specially during the first charge of scrap metal.

Fig 18 shows the normalized one-week, 10-minute-interval $\mathrm{P}_{\mathrm{st}}$ measurements.

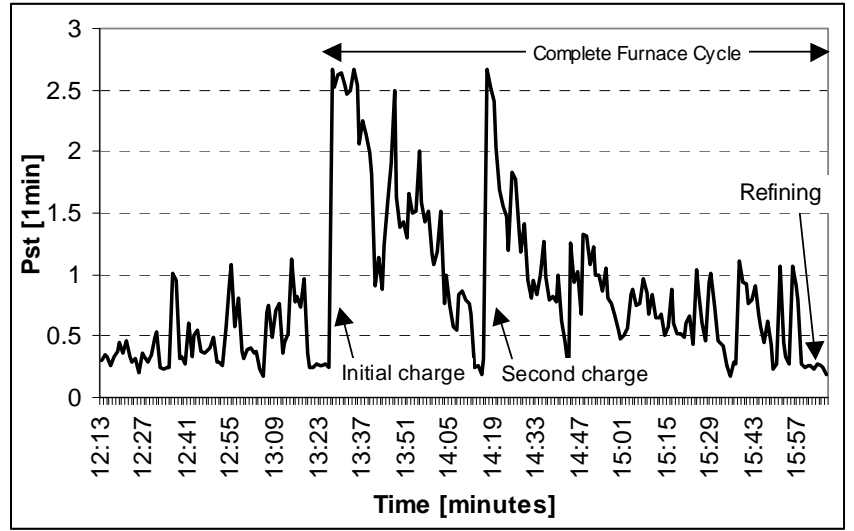

Fig. 17: $\mathrm{P}_{\mathrm{st}}$ measurements during a complete furnace cycle.

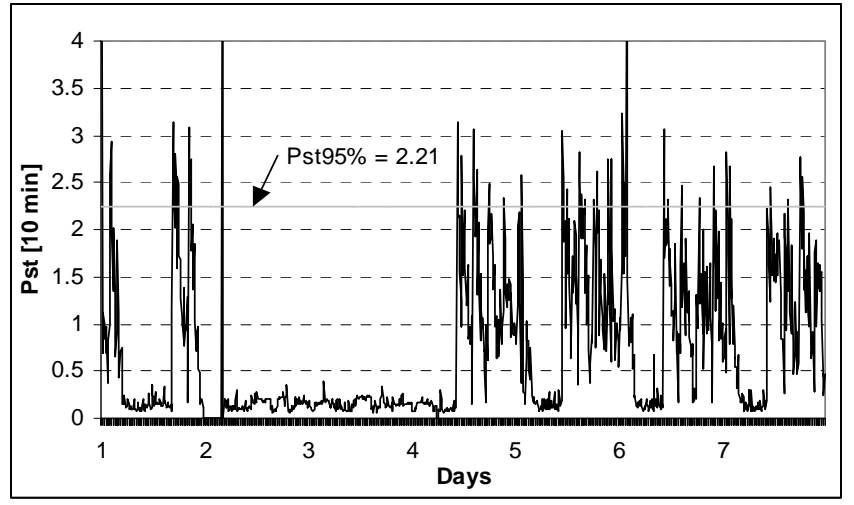

Fig. 18: $\mathrm{P}_{\mathrm{st}}$ measurements during a week.

The furnace cycle depicted in Fig. 17 was 2 and a half hour long and the furnace was recharged twice after the initial charge. It is interesting to note that the perturbation level decays as the metal becomes liquid and the arc becomes shorter and more stable. The statistical results obtained from the normalized flicker measurement are presented in Table III.

Table III: Statistical results of flicker measurement.

\begin{tabular}{|c|c|}
\hline Total observations of 10 minutes & 1008 \\
\hline $\mathrm{P}_{\text {st95\% }}$ & 2.21 \\
\hline Observations with $\mathrm{P}_{\text {st }}>1$ & 288 \\
\hline Percent of measurement with $\mathrm{P}_{\mathrm{st}}>1$ & $28.6 \%$ \\
\hline
\end{tabular}

The value of $\mathrm{P}_{\mathrm{st} 95 \%}=2.21$ obtained is above the limits of European and Argentinian Standards.

Verification of $\boldsymbol{P}_{s t 95 \%}$ and $\boldsymbol{K}_{\text {st }}$ values obtained from measurements
The CENELEC EN 50160 European Standard specifies the main characteristics of the voltage at the customers supply terminals in public low and medium voltage distribution systems under normal operating conditions.

According to that Standard, the arc furnace flicker could be estimated by:

$$
\mathrm{P}_{\mathrm{st} 99 \%}=48 \ldots \ldots . .85 \frac{S_{s c f}}{S_{s c}}
$$

If $\mathrm{P}_{\mathrm{st} 99 \%} \approx 1.25 \mathrm{P}_{\mathrm{st} 95 \%}$ then:

$$
\mathrm{P}_{\mathrm{st95 \%}} \approx 40 \ldots . . .70 \frac{S_{s c f}}{S_{s c}}
$$

For the arc furnace studied:

$$
\mathrm{P}_{\mathrm{st} 95 \%} \approx 40 \ldots . . .70 \frac{5.6}{180}=1.3 . \ldots . .2 .2
$$

This value is similar to the one obtained in measurements.

On the basis of the results of a large number of measurements taken in arc furnace installations, a simple empirical prediction formula to estimate flicker level at point of PCC have been recommended for a.c. furnaces:

$$
\mathrm{K}_{\mathrm{st}}=P_{s t 95 \%} \frac{S_{\mathrm{sc}}}{S_{\mathrm{scf}}}=70
$$

$\mathrm{S}_{\mathrm{scf}}=$ The short circuit power of the arc furnace at the PCC. $\mathrm{S}_{\mathrm{sc}}=$ Short circuit power of the network at the PCC.

$\mathrm{K}_{\mathrm{st}}$ is a flicker emission coefficient. A value of $\mathrm{K}_{\mathrm{st}}$ in the range from 40 to 80 should be considered realistic for modern a.c. arc furnaces.

\section{Flicker situation of the steelworks according to the Argentinian Standards}

The emission limit for flicker according to the Argentinian Standard Res. 99/97 [1] of ENRE is dependent of the short circuit power of the system at the PCC and the power of the consumer, as can be seen in Table IV.

Table IV: Individual Emission Limits according to Res. 99/97

\begin{tabular}{|c|c|}
\hline $\begin{array}{c}\text { MV and HV users } \\
(\mathbf{1 k V}<\mathbf{U} \leq \mathbf{2 2 0} \mathbf{~ k V}) \\
\mathbf{K} 2=\mathbf{S}_{\mathbf{L}} / \mathbf{S}_{\mathbf{s c}}\end{array}$ & $\begin{array}{c}\text { Individual Emission Limits } \\
\mathbf{( P S T )}\end{array}$ \\
\hline $\mathrm{K}_{2} \leq 0,005$ & 0,37 \\
\hline $0,005<\mathrm{K} 2 \leq_{0,01}$ & 0,46 \\
\hline $0,01<\mathrm{K} 2 \leq_{0,02}$ & 0,58 \\
\hline $0,02<\mathrm{K} 2 \leq_{0,03}$ & 0,67 \\
\hline $0,03<\mathrm{K} 2 \leq_{0,04}$ & 0,74 \\
\hline $0,04<\mathrm{K} 2$ & 0,79 \\
\hline
\end{tabular}

Based on that resolution it is possible to estimate:

- Flicker compensation required for the arc furnace.

- The minimum short circuit power of the network to avoid flicker compensation.

- Flicker propagation in different points of the power system. 


\section{Flicker compensation ratio}

The arc furnace apparent power could be determined according to the power factor limit described in Res. 99/97.

$$
S_{L}=\frac{2.5 \times 10^{6}}{0.85}=2.95 \mathrm{MVA}
$$

It is possible now to estimate the ratio between the steelworks apparent power and the short circuit level at the steelworks substation.

$$
K_{2}=\frac{S_{L}}{S_{s c}}=\frac{2.95 \times 10^{6}}{180 \times 10^{6}}=0.016
$$

With this $\mathrm{K}$ factor it is possible to obtain by Res. 99/97 the maximum flicker that could be emitted by the steelwork.

$$
\mathrm{P}_{\text {stLimit }}=\leq 0.58
$$

According to this value it is possible to estimate the flicker compensation ratio:

$$
\frac{P_{\text {streal }}}{P_{\text {st } \lim \text { it }}}=\frac{2.2}{0.58}=3.8
$$

\section{Flicker propagation}

The relationship between flicker in two nodes of the network and the corresponding short circuit power at those nodes could be estimated by:

$$
P_{s t 2}=P_{s t 1} \frac{S_{c c 1}}{S_{c c 2}}
$$

The results obtained are shown in Table V.

Table V: Flicker propagation

\begin{tabular}{|c|c|c|c|}
\hline & $\begin{array}{c}\text { Steelworks } \\
\text { Busbar } \\
(\mathbf{1 3 . 2 ~ k V )}\end{array}$ & $\begin{array}{c}\text { PCC } \\
\mathbf{( 1 3 . 2 ~ k V )}\end{array}$ & $\begin{array}{c}\text { HV } \\
\text { network } \\
(\mathbf{1 3 2} \mathbf{~ k V})\end{array}$ \\
\hline $\begin{array}{c}\text { Short circuit } \\
\text { Power (MVA) }\end{array}$ & 180 & 330 & 2000 \\
\hline $\begin{array}{c}\text { Flicker level } \\
\left(\mathbf{P}_{\text {st95\%) }}\right.\end{array}$ & 2.2 & 1.2 & 0.2 \\
\hline
\end{tabular}

\section{Minimum network short circuit power to avoid compensation}

With the objective to comply with Res. 99/97, and according to the first line of Table IV:

$$
\frac{S_{L}}{S_{c c}}=K_{2} \leq 0.005 \quad \text { and } \quad \mathrm{P}_{\text {stLimit }}=0.37
$$

For the present case:

Then results:

$$
\mathrm{P}_{\mathrm{st} 1}=2.2 \quad \text { and } \quad \mathrm{S}_{\mathrm{cc} 1}=180 \mathrm{MVA}
$$

$$
\mathrm{S}_{\mathrm{cc} 2}>1100 \mathrm{MVA}
$$

If the short circuit power at the steelworks busbar is 1100 MVA or more, there is no need to flicker compensation. This technical solution could be implemented by connecting the steelworks to the immediately high voltage level (132 kV).

\section{IV.2 Harmonics}

The Argentinian Standard is ENRE's Res. 184/00. Reference levels to be met are those which should be guaranteed at each supply point. Transgression probability should not be above $5 \%$ a week.

The adopted values for harmonics depend on the voltage level. The results obtained for one-week measurements of voltage levels are shown in Fig 19, and summarized in Table VI. The reference levels for voltage distortion are also shown.

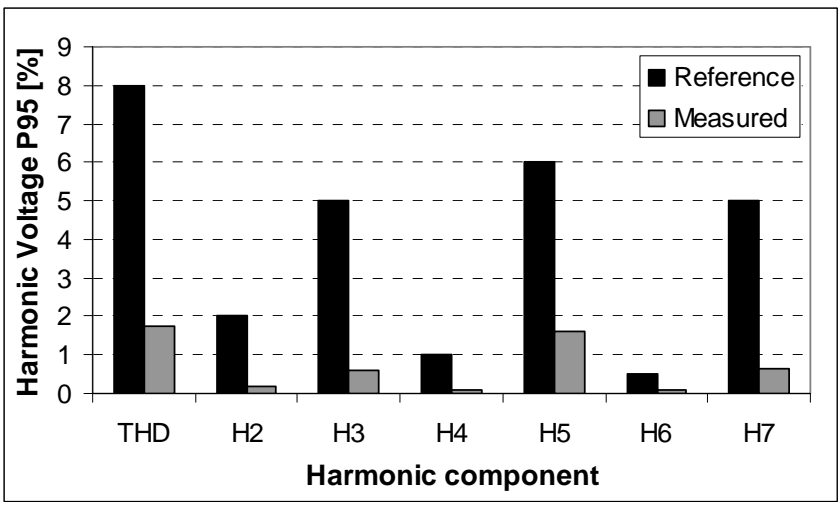

Fig. 19: Voltage harmonics reference levels and measured.

Table VI: Reference levels for voltage harmonics according to ENRE and voltage harmonics measured

\begin{tabular}{|c|c|c|c|c|c|c|c|}
\hline & THD & H2 & H3 & H4 & H5 & H6 & H7 \\
\hline $\begin{array}{c}\text { ENRE } \\
\text { Limits }\end{array}$ & 8 & 2 & 5 & 1 & 6 & 0.5 & 5 \\
\hline Medium & 1.01 & 0.11 & 0.47 & 0.05 & 0.80 & 0.03 & 0.34 \\
\hline P95 & 1.74 & 0.19 & 0.61 & 0.11 & 1.61 & 0.07 & 0.64 \\
\hline Maximum & 2.14 & 0.36 & 0.78 & 0.19 & 1.97 & 0.13 & 0.97 \\
\hline
\end{tabular}

According to Res. 99/97 [1], to evaluate the emission limits, the harmonics currents should be referred to the current obtained from the maximum load demand of 2.5 MW and an indicated power factor of 0.85 .

The results obtained for one-week measurements of current levels are shown in Fig 20, and summarized in Table VII. The reference levels for current distortion are also depicted.

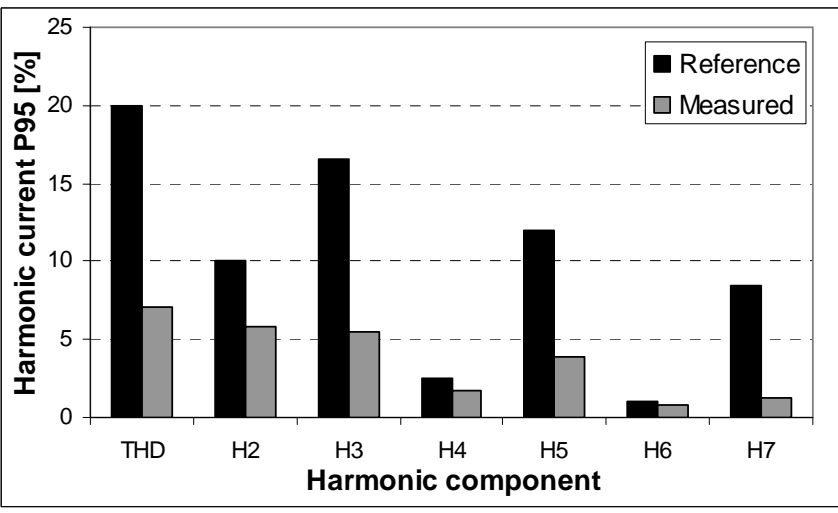

Fig. 20: Emission limits and current harmonics measured. 
According to IEEE 519 [6] the current distortion limits for general distribution systems are based on the size of the load with respect to the size of the power system to which the load is connected. The ratio $\mathrm{I}_{\mathrm{sc}} / \mathrm{I}_{\mathrm{L}}$ is the ratio of the short circuit current available at the PCC, to the maximum fundamental load current. The even harmonics are limited to $25 \%$ of the odd harmonics limits. In the present case the $\mathrm{I}_{\mathrm{sc}} \mathrm{I}_{\mathrm{L}}$ ratio is:

$$
\frac{I_{s c}}{I_{L}}=61
$$

This ratio is important to choose the IEEE 519 Standard maximum corresponding harmonics limits. This limits are shown in Table VII.

Table VII: Emission limits for current harmonics according to ENRE and IEEE 519 and current harmonics measured

\begin{tabular}{|c|c|c|c|c|c|c|c|}
\hline & TDD & H2 & H3 & H4 & H5 & H6 & H7 \\
\hline $\begin{array}{c}\text { ENRE } \\
\text { Limits }\end{array}$ & 20 & 10 & 16.6 & 2.5 & 12 & 1 & 8.5 \\
\hline $\begin{array}{c}\text { IEEE } \\
\mathbf{I}_{\text {sc }} / \mathbf{I}_{\mathbf{L}} \\
\mathbf{5 0}<\mathbf{1 0 0}\end{array}$ & 12 & 2.5 & 10 & 2.5 & 10 & 2.5 & 10 \\
\hline Medium & 3.10 & 1.73 & 1.87 & 0.53 & 1.45 & 0.25 & 0.45 \\
\hline P95 & 9.14 & 5.85 & 5.47 & 1.76 & 3.92 & 0.82 & 1.26 \\
\hline Maximum & 16.12 & 11.97 & 9.11 & 3.23 & 5.79 & 1.62 & 2.01 \\
\hline
\end{tabular}

In IEEE 519 Standard it is not indicated if the emission limits must be applied to the medium, the $\mathrm{P}_{95 \%}$ or to the maximum current harmonics measured. If we choose the $P_{95 \%}$ value, the second current harmonic is above the limit.

\section{Conclusions}

In the first section of this paper a complete characterization of the several phases of operation of an electric arc furnace is included.

The short circuit test of the arc furnace is of fundamental importance in determining its parameters. A single phase arc furnace model obtained from test results is suitable to describe the different phases of operation of the arc furnace. Test results are presented to support the validity of using a single phase arc furnace model to represent the furnace operation.

Test results presented also describe power factor, active, and reactive power variations, and current harmonics content, in the different phases of operation of the arc furnace. The current harmonic content measured during initial melting and refining is similar to the theoretical values described in [6].

The flicker level measured in the steelworks busbar is high and exceeds the reference level at the PCC. Flicker compensation ratio needed for the determination of compensator rating is calculated.

Another technical solution to mitigate flicker is presented. If the short circuit power at the steelworks busbar is 1100 MVA or more, there is no need to flicker compensation. This solution could be implemented by connecting the steelworks to the immediately high voltage level (132 $\mathrm{kV}$ in this case).

The current harmonics levels measured during initial melting period are high, but in the normalized one-week measurement only the TDD is above the emission limits.
In this particular case it is possible to conclude that the furnace is not an important disturbing load.

\section{REFERENCES}

Books:

[1] Reactive Power Control In Electric Systems. Timothy J. E. Miller. John Wiley \& Sons, Inc. 1982. ISBN 0-471-86933-3.

[2] Static Synchronous Compensator (STATCOM) for Arc Furnace and Flicker Compensation. WG B4. 19. CIGRE Publication. December 2003

Periodicals:

[3] "Development of a model for predicting flicker from electric arc furnaces”. G. Manchur and C. C. Erven. IEEE Transactions on Power Delivery, Vol 7, No. 1, January 1992.

\section{Papers from Conference Proceedings (Published):}

[4] "Power Quality Aspects of Arc Steel Melting Furnace. A case Study. Ljubomir Nikoloski and Goran Rafajlovski. 10 $0^{\text {th }}$ Mediterranean Conference, MeleCon 2000 Vol. III pp. 916-919. 0-7803-6290-X.

Standards:

[5] Anexo a la Resolución ENRE 99/97. Base Metodológica para el Control de la Emisión de Perturbaciones. Etapa 2.

[6] Anexo a la Resolución ENRE 184/00. Base Metodológica para el Control de la Calidad del Producto Técnico. Etapa 2.

[7] IEEE Std. 519-1992. Recommended Practices and Requirements for Harmonic Control in Electrical Power Systems.

[8] IEC 61000-3-3. Electromagnetic Compatibility (EMC). Part 3: Limits. Section 3: Limitation of voltage fluctuations and flicker in low-voltage supply systems for equipment with rated current $\leq 16 \mathrm{~A}$.

[9] IEC 61000-3-5. Electromagnetic Compatibility (EMC). Part 3: Limits. Section 5: Limitation of voltage fluctuations and flicker in low-voltage power supply systems for equipment with rated current $>$ than $16 \mathrm{~A}$.

\section{BIOGRAPHIES}

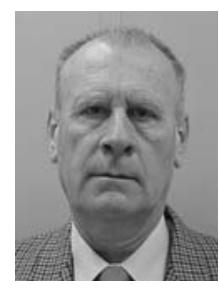

Pedro Eduardo Issouribehere: was born in Balcarce, Argentina, on September 19, 1945. He received the Engineer degree from La Plata National University, Buenos Aires, Argentina, in 1971. He has worked as a researcher for IITREE-LAT since 1970, a Research and Development University Institute. He is a specialist in electronic equipment development for non conventional electrical measurements.

$\mathrm{He}$ is in charge of the IITREE-LAT Technical Assistance Area. Currently his research interests are power quality and electromagnetic environmental impact, and their applications in Argentinian and South American electrical markets.

$\mathrm{He}$ is a full professor at the Electrical and Electronic Engineering Department, La Plata National University, Argentina.

He is currently the President of CIGRÉ Technical Committee, Argentina.

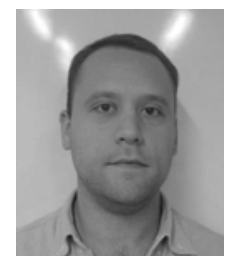

Fernando Issouribehere: was born in La Plata, Argentina, on March 22, 1975. He received the Engineer degree from La Plata National University, Buenos Aires, Argentina, in 1999. He has worked as a researcher for IITREE-LAT since 2000.

His research interests include power electronics, power quality, and power systems operation and control.

$\mathrm{He}$ is an assistant professor at the Electrical and Electronic Engineering Department, La Plata National University.

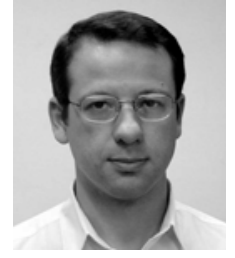

Gustavo A. Barbera: was born in La Plata Argentina, on February 20, 1972. He received the Engineer degree from La Plata National University, Buenos Aires, Argentina, in 1996.

He has worked as a researcher for IITREE-LAT of UNLP since 1996. He carries out and processes power quality measurements, especially regarding voltage level and disturbance studies.

He is a professor at the Electrical and Electronic Engineering Department, La Plata National University. 